\title{
Chromosome damage in early embryo and endosperm development in crosses involving the preferentially transmitted $\mathbf{4} \mathbf{S}^{\prime}$ chromosome of Aegilops sharonensis
}

\author{
I. P. KING \& D. A. LAURIE \\ Cereals Department, Cambridge Laboratory, Jl Centre, Coiney Lane, Norwich NRA 7UJ, U.K.
}

\begin{abstract}
Chromosome aberrations during early embryo and endosperm development were analysed in reciprocal crosses between Chinese Spring wheat monosomic for chromosome 4B (M4B) and a Chinese Spring substitution line in which chromosome 4B was replaced by the homoeologous $4 S^{1}$ chromosome of Aegilops sharonensis [ $\left.4 \mathrm{~S}^{\prime}(4 \mathrm{~B})\right]$. In $\mathrm{M} 4 \mathrm{~B} \times 4 \mathrm{~S}^{\mathrm{1}}(4 \mathrm{~B})$ crosses, chromosome aberrations were common in both embryo and endosperm, while in $4 S^{1}(4 B) \times M 4 B$ crosses they were confined to the endosperm and occurred at a lower frequency. Chromosome aberrations also occurred in the endosperms of self-pollinated $4 \mathrm{~S}^{\prime}(4 \mathrm{~B})$ plants. The types of aberration were similar to those seen at first pollen grain mitosis in plants monosomic for chromosome $4 \mathrm{~S}^{1}$, and which are thought to be the basis of its preferential transmission. It is therefore likely that a single mechanism is responsible for aberrations in meiocytes, embryos and endosperms. The implications of chromosome aberrations during early seed development for the agronomic applications of the $4 S^{1}$ chromosome are discussed.
\end{abstract}

Keywords: Aegilops sharonensis, chromosome fragmentation, chromosome $4 S^{\prime}$, embryo and endosperm development, preferential transmission, Triticum aestivum.

\section{Introduction}

A number of workers have shown that certain $\mathrm{C}$ and $\mathrm{S}$ genome chromosomes are preferentially transmitted when introduced into hexaploid wheat (Endo \& Tsunewaki, 1975; Maan, 1975; Miller et al., 1982). The mechanism by which chromosome $4 \mathrm{~S}^{\mathrm{l}}$ of Aegilops sharonensis is preferentially transmitted in wheat was investigated by Finch et al., (1984), who showed that in plants monosomic for chromosome $4 \mathrm{~S}^{\mathrm{l}}$, approximately 50 per cent of meiocytes at the first post-meiotic mitosis contained chromosome fragments. These fragments, which were termed SSs (separated segments), 'seemed to be comprised of a pair of equal length parts of two sister chromatids'. It was proposed that meiospores that lacked chromosome $4 S^{\mathrm{l}}$ underwent chromosome fragmentation, which prevented normal development, while meiospores containing chromosome $4 S^{1}$ developed normally. Thus only gametes containing chromosome $4 \mathrm{~S}^{\mathrm{l}}$ contributed to the next generation. The frequency of transmission of chromo- some $4 S^{1}$ through both the male and female gametes, when in the monosomic condition in a range of genetic backgrounds, has been shown to be at least 97.8 per cent (King et al, 1991c).

It has also been shown that in certain situations progeny derived from plants containing preferentially transmitted chromosomes possess chromosome aberrations, including deletions, translocations, ring and telocentric chromosomes (Endo, 1985, 1988a, b; Tsujimoto \& Tsunewaki, 1985, Endo \& Mukai, 1988). In the case of chromosome $4 S^{\mathrm{l}}$, the highest frequency of aberrations occurs when the Chinese Spring $4 \mathrm{~S}^{\mathrm{I}}(4 \mathrm{~B})$ substitution line is used as the male parent in crosses to Chinese Spring monosomic for chromosome 4B. (Wheat chromosome nomenclature follows the recommendation of the 7th International Wheat Genetics Symposium, 1988.) Chromosome aberrations were sometimes observed in both homologues of a particular chromosome (Endo, 1988a), indicating that at least some of the aberrations occurred after fertilization. In contrast, when $4 S^{1}(4 B)$ was used as the female parent in 
crosses with Chinese Spring, or when the $4 \mathrm{~S}^{1}$ disomic addition was self-pollinated, the progeny did not contain chromosome aberrations (Endo, 1988a).

Chromosome $4 S^{1}$ is presumably responsible for chromosome fragmentation in both meiospores and developing embryos, but while previous work had addressed the mechanism of preferential transmission and the chromosome constitution of the progeny, little is known about the timing or extent of chromosome damage in the developing seed. The latter aspect needs to be understood because it has important implications for the use of chromosome $4 \mathrm{~S}^{1}$ in wheat improvement programmes. The present work describes chromosome aberrations occurring during early seed development and their relationship to aberrations in meiospores, and discusses the implications of chromosome fragmentation during early seed development for the agronomic applications of chromosome $4 \mathrm{~S}^{!}$.

\section{Materials and methods}

\section{Plant materials}

Reciprocal crosses were made between Chinese Spring wheat ( $T$. aestivum) monosomic for chromosome 4B (Sears, 1954), subsequently referred to as M4B, and a Chinese Spring substitution line in which both 4B chromosomes had been replaced by chromosome $4 \mathrm{~S}^{\mathrm{l}}$ from Ae. sharonensis (Miller et al., 1982). This line is referred to as $4 \mathrm{~S}^{\mathrm{l}}(4 \mathrm{~B})$. Three control crosses were also investigated. These were: (i) M4B $\times$ euploid Chinese Spring (CS); (ii) M4B $\times$ Chinese Spring carrying an additional pair of $4 \mathrm{R}$ chromosomes from rye (Secale cereale) cv. Imperial (CS4R) (Driscoll \& Sears, 1971) (this control cross was made to determine if homoelogous group 4 alien chromosomes other than $4 \mathrm{~S}^{1}$ induced chromosome aberrations); and (iii) selfpollinations of the $4 S^{\prime}(4 B)$ substitution line.

\section{Crossing procedure and cytological methods}

Plants which were used as female parents were grown in a glasshouse until a few days before anthesis in the leading tiller when they were transferred to a controlled environment cabinet at $20^{\circ} \mathrm{C} \pm 1^{\circ} \mathrm{C}$ with a 16 -h light period. About 2 days before anthesis, plants were emasculated and after a further 2 days, pollinated. Ovaries were removed from pollinated spikes and selffertilized $4 S^{\mathrm{I}}(4 \mathrm{~B})$ spikes at intervals between 7 and 72 $\mathrm{h}$, fixed in a 3:1 ethanol:glacial acetic acid solution and stored at $4^{\circ} \mathrm{C}$. Ovaries were then rinsed in distilled water for $1 \mathrm{~h}$, hydrolysed in $1 \mathrm{M} \mathrm{HCl}$ at $60^{\circ} \mathrm{C}$ for $12 \mathrm{~min}$ and stained in Feulgen solution for at least $2 \mathrm{~h}$ at room temperature. Embryo sacs were dissected from ovules in distilled water, unwanted material was removed and the specimen was flooded with 45 per cent acetic acid under a coverslip. Additional staining was provided by adding 1 per cent acetic orcein.

\section{Results}

\section{Embryo development}

(a) $M 4 B(O) \times 4 S^{l}(4 B)\left(0^{\prime}\right)$ crosses. Zygotes (the single cells formed by the fusion of the male and female gametes) at interphase were the earliest developmental stage observed. None of the 40 examined appeared to be abnormal (Table 1). Four out of the 140 two-celled embryos at interphase ( 2.9 per cent) were abnormal in that they contained a single micronucleus. However, 36 out of 52 (69.2 per cent) cells at telophase from twocelled embryos contained either one or two chromosome fragments, usually one or two fragments per cell (Fig. 1a). Of the 71 fragments observed, 57 were type I (Fig. 2a) while 10 were type II (Fig. 2b), and the remaining four appeared to be composed of a single chromatid (Fig. 1b). Thirty-two out of 96 (33 per cent) four-celled embryos, in which the nuclei were at interphase, had micronuclei (one or two per cell) and occasionally a chromosome fragment. Micronuclei were presumably derived from chromosome fragments which were not included in the main nuclei during the previous cell division. Sixteen embryos consisting of 16-32 cells at interphase were observed and all appeared to be normal. These observations indicate a peak of chromosome damage early in embryo development.

(b) $4 S^{\prime}(4 B)\left(\right.$ (O) $\times M 4 B\left(C^{\prime}\right)$ crosses. Twenty zygotes (at interphase), 37 two-celled embryos (at interphase and telophase), 14 four-celled embryos (at interphase) and 17 embryos with between 16 and 32 cells (at interphase) were observed. All 88 appeared normal (Table 1).

(c) Control crosses. All 64 embryos from M4B $\times$ CS appeared normal. One four-celled M4B $\times$ CS4R embryo cell contained a micronucleus but this was the only abnormality seen in the 53 embryos examined (Table 1). A total of 66 embryos with either one, two, three, four, seven and eight cells were observed in selfpollinations of $4 \mathrm{~S}^{\prime}(4 \mathrm{~B})$ plants, only one of which was abnormal. The aberrant embryo (two-celled) had a chromatin bridge and had an abnormal plane of cell division so that one nucleus was constricted by the newly forming cell-wall. 


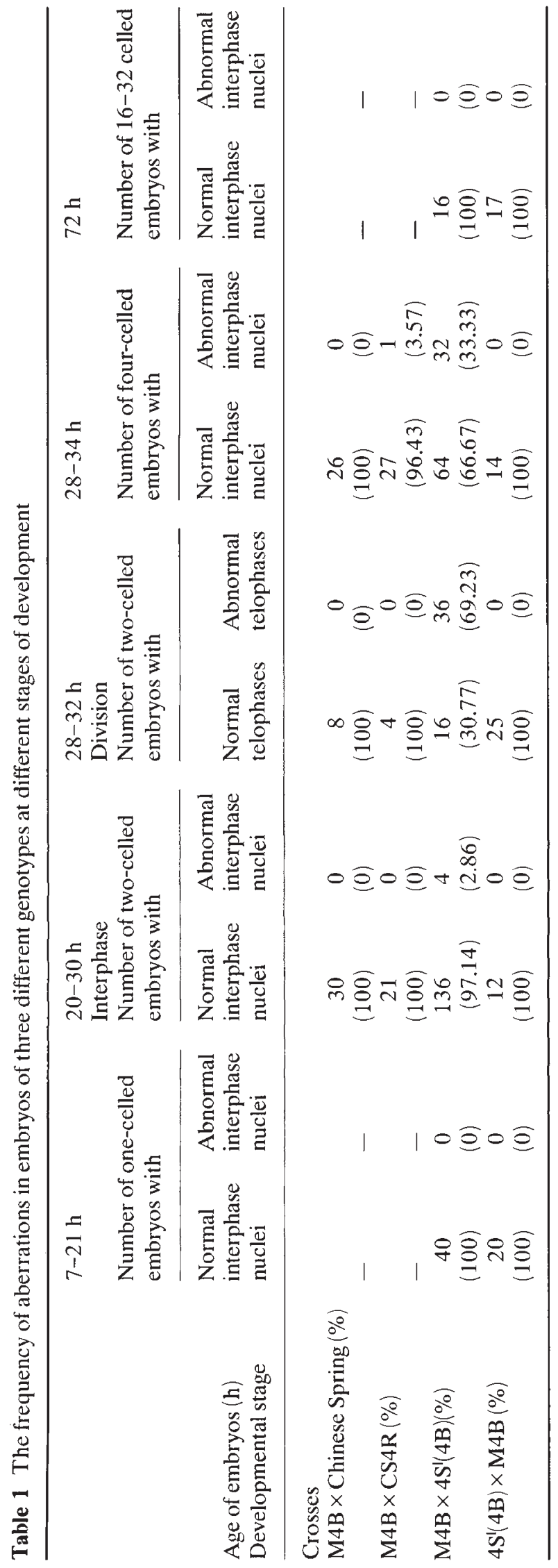

\section{Endosperm development}

(a) $M 4 B(O) \times 4 S^{l}(4 B)\left(0^{\prime}\right)$ crosses. Abnormalities were first noted at the two nucleate stage. Five out of 34 (17 per cent) two-nucleate endosperms at interphase were abnormal, with chromatin bridges, abnormally shaped nuclei and or micronuclei. Higher frequencies of aberrations were observed at slightly later stages. Twenty endosperms undergoing the fourth nuclear division cycle $(8 \rightarrow 16$ nuclei) and 10 endosperms undergoing the fifth nuclear division cycle $(16 \rightarrow 32$ nuclei) were observed (Table 2). Fifteen of the former (75 per cent) and all of the latter had aberrations. The types of aberrations observed were similar to those seen in embryos but the number of chromosome fragments per division tended to be higher (compare Figs $3 \mathrm{a}$ and $\mathrm{c}$ with $1 \mathrm{a}$ and $\mathrm{b}$ ), with some endosperm divisions having more than 10 fragments, and the size of the fragments in the endosperm tending to be greater, often appearing to be longer than some whole chromosomes (Fig. 3b). These large chromosome fragments were presumably fusion products of smaller fragments. In addition, chromatin bridges were frequently observed in endosperm divisions (Fig. 3d) but were not seen in embryos.

In contrast, six 3-day-old endosperms, each with approximately 1,000 cells at interphase, appeared normal with the exception of a few misshapen nuclei. Four further 3-day-old endosperms, each with approximately 600 nuclei undergoing division, did not contain chromosome fragments. However, these four endosperms contained, respectively, 10 , four, two and one telophase nuclei with chromatin bridges. As in the embryo, these results suggest that the frequency of chromosome aberrations in the endosperm reaches a peak during a relatively short period early in the development.

(b) $4 S^{\prime}(4 B)\left(O \times M 4 B\left(0^{*}\right)\right.$ crosses. Fifteen 16-nucleate endosperms and 12 32-nucleate endosperms were observed. Seven of the former (46.7 per cent) and nine of the latter ( 75 per cent) contained aberrations including abnormal shaped nuclei, bridges, micronuclei and chromosome fragments (Table 2). The frequency of aberrations in 64-nucleate endosperms was considerably lower (Table 2), and long chromosome fragments were not observed. This again suggests that aberrations are most common at specific early stages of development. However, the frequency of aberrations in $4 S^{\prime}(4 B)$ $($ $) \times \mathrm{M} 4 \mathrm{~B}\left(\mathrm{O}^{\prime}\right)$ endosperms was less then in M4B $(\wp) \times 4 \mathrm{~S}^{1}(4 \mathrm{~B})\left(0^{\prime}\right)$ endosperms (Table 2).

(c) Control crosses. No abnormalities were observed in $14 \mathrm{M} 4 \mathrm{~B} \times \mathrm{CS}$ and $15 \mathrm{M} 4 \mathrm{~B} \times \mathrm{CS} 4 \mathrm{R}$ eight-nucleate 
Fig. 1 (a) A cell from a two-celled M4B $\times 4 S^{\prime}(4 B)$ embryo at telophase. The closed triangle indicates a type I fragment (see Fig. 2a). (b) A single cell from a two-celled $\mathrm{M} 4 \mathrm{~B} \times 4 \mathrm{~S}^{\mathrm{l}}(4 \mathrm{~B})$ embryo at telophase showing a type I fragment $(\boldsymbol{\Delta})$ and a fragment composed of a single chromatid $(\Delta)$.

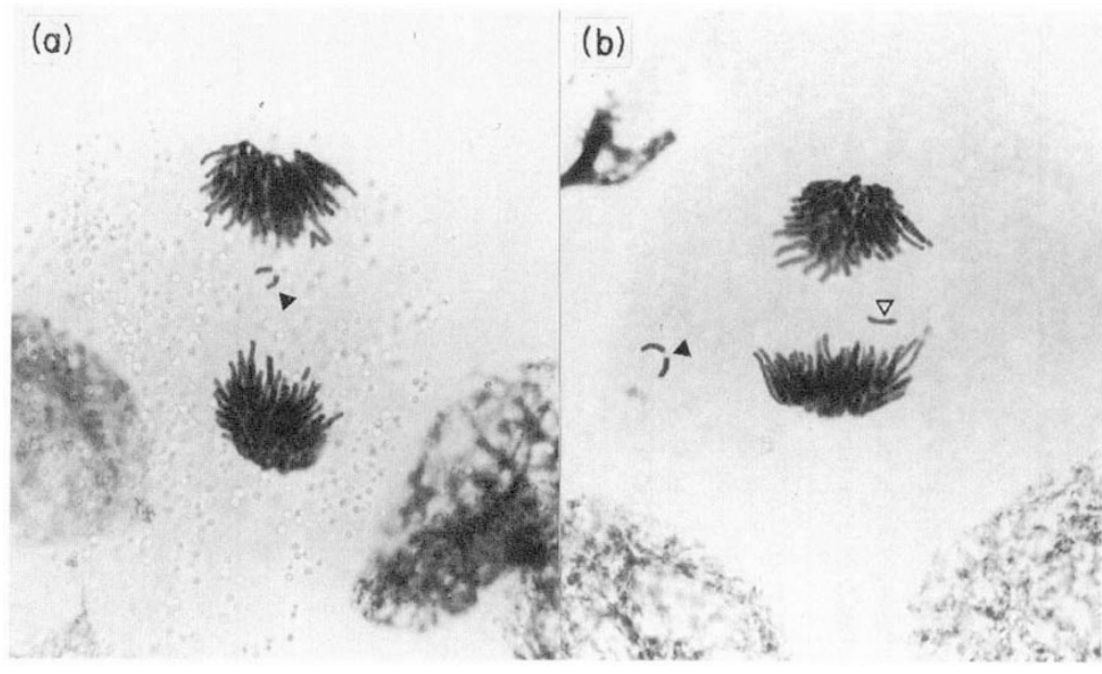

(a) Typel fragments

(i)

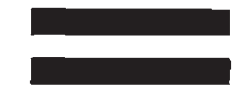

Double chromatid fragments

(ii)
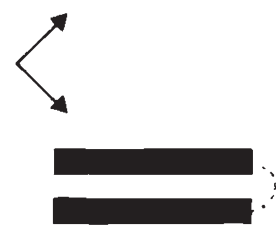

Chromatids close together

I separated by no more

then one chromatid width)

(b)

Type II fragments
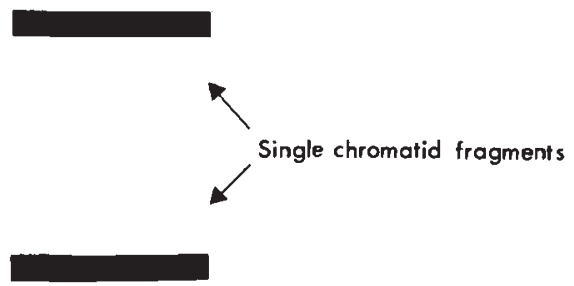

Fig. 2 (a) Type I fragments appear to be composed of two equal lengths of chromatid (i) which occasionally appear to be loosely associated at one end (ii). (b) Type II fragments are composed of a single chromatid fragment. These fragments appear to be derived from the separation of the two chromatid fragments making up a type I fragment.

endosperms undergoing division. However, aberrations were found in endosperms produced by selfpollination of $4 \mathrm{~S}^{\mathrm{I}}(4 \mathrm{~B})$ plants. A total of 44 endosperms were observed (Table 2). The types of aberration observed were similar to those in $4 \mathrm{~S}^{\mathrm{l}}(4 \mathrm{~B}) \times \mathrm{M} 4 \mathrm{~B}$ endosperms (Fig. 4a and b). For example, chromatin bridges, which resulted in the failure of nuclei to separate properly (Fig, 4c), tended to give rise to grossly abnormal nuclei after further rounds of replication (Fig. 4d). In six further cases a small number (1, three cases; 4, two cases and 3, one case respectively) of large nuclei were observed in embryo sacs where the stage of embyro development indicated that 16-64 nuclei should have been present. These large nuclei probably resulted from failure to separate daughter nuclei. The frequency of chromosome aberrations in self-pollinated $4 \mathrm{~S}^{1}(4 \mathrm{~B})$ plants was similar to that in the $4 \mathrm{~S}^{\mathrm{l}}(\mathrm{4B}) \times \mathrm{M} 4 \mathrm{~B}$ endosperms and considerably less then in $\mathrm{M} 4 \mathrm{~B} \times 4 \mathrm{~S}^{\mathrm{Y}}(4 \mathrm{~B})$ endosperms.

\section{Discussion}

\section{(a) Post fertilization aberrations induced by the $4 S^{\prime}$ chromosome}

The results show that a burst of chromosome aberrations occurs during early embryo and endosperm development in crosses involving chromosome $4 \mathrm{~S}^{1}$ from Ae. sharonensis. Chromosome aberrations occur in the embryo only when the chromosome $4 \mathrm{~S}^{l}$ donor is the male parent while the endosperm, aberrations occur when the $4 \mathrm{~S}^{1}$ donor is either the male or female and when $4 \mathrm{~S}^{\mathrm{l}}(4 \mathrm{~B})$ plants are self-pollinated. The results from embryos are consistent with previous work on the cytology of progeny plants (Endo, 1988a), where chromosome aberrations were only found when the $4 \mathrm{~S}^{1}$ donor was the male parent. In that work, the highest frequency of individuals with chromosome aberrations was found in plants from $\mathrm{M} 4 \mathrm{~B} \times 4 \mathrm{~S}^{\mathrm{l}}(4 \mathrm{~B})$ crosses. Overall, 52.7 per cent of nullisomic $4 \mathrm{~B}$ plants and 28.6 per cent of monosomic 4B plants had chromosome aberrations.* In contrast, only 8.5 per cent of progeny from 


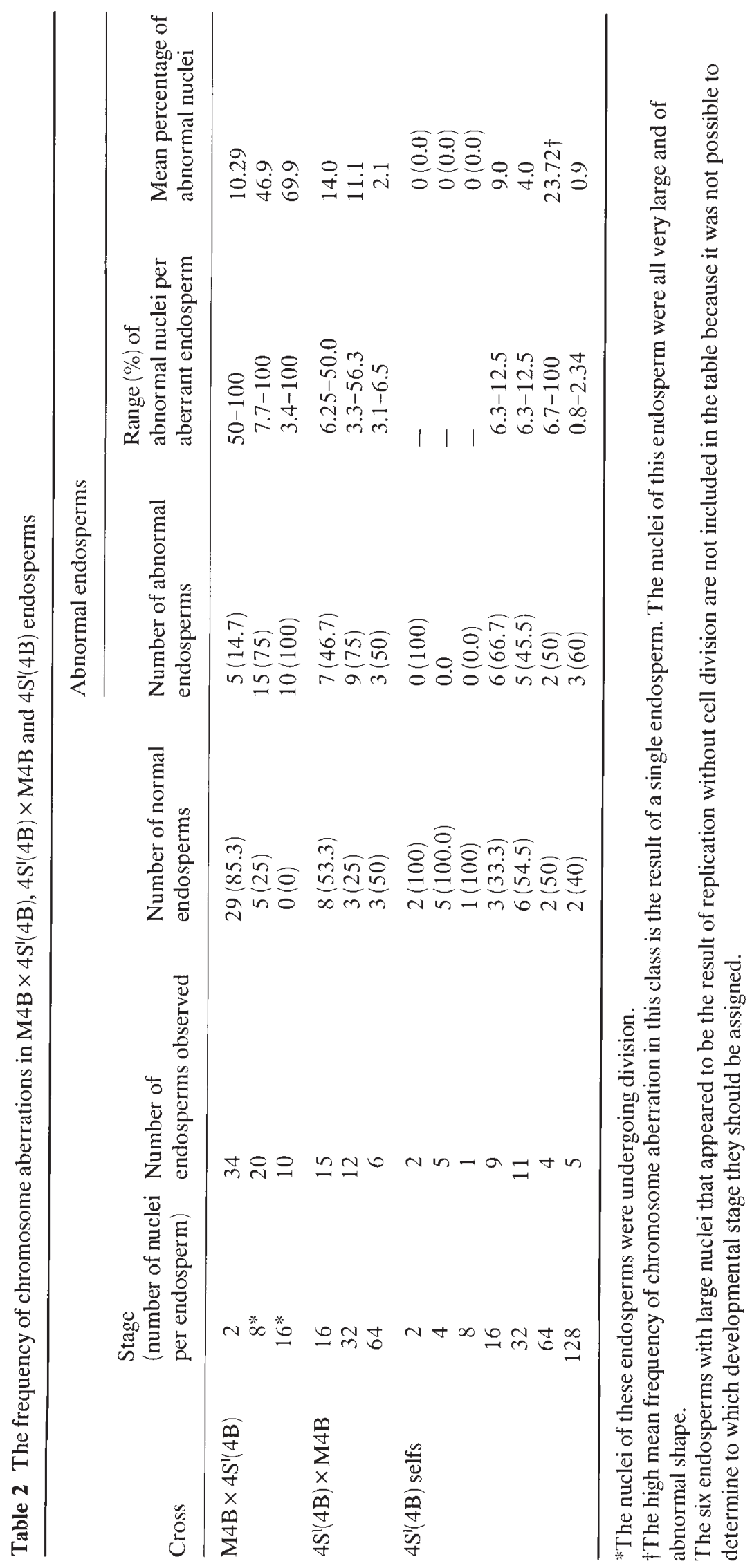


Fig. 3 Endosperm nuclei from $\mathrm{M} 4 \mathrm{~B} \times 4 \mathrm{~S}^{\prime}(4 \mathrm{~B})$ crosses (a) Prophase showing type I ( $\boldsymbol{\Delta})$ and type II fragments $(\Delta)$. (b) Metaphase showing a large acentric fragment $(\boldsymbol{\Delta})$ and a small acentric fragment $(\Delta)$. (c) Telophase showing type I fragments ( $\boldsymbol{\Delta}$ ) and a micronucleus $(\Delta)$. (d) Telophases showing chromatin bridges $(\boldsymbol{\Lambda})$.
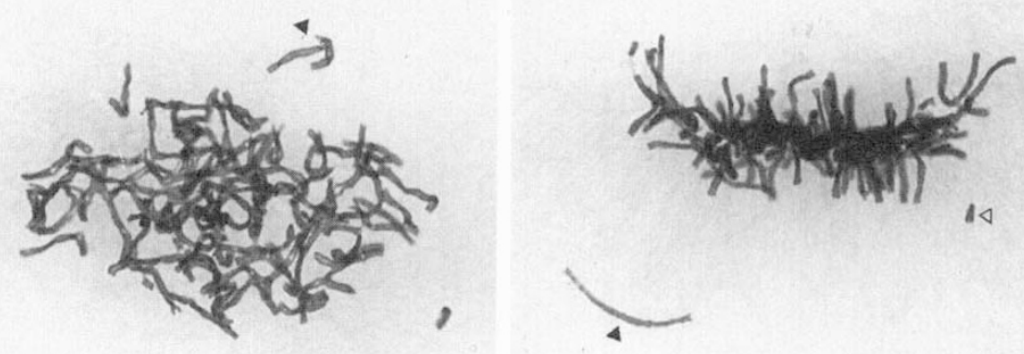

(a)
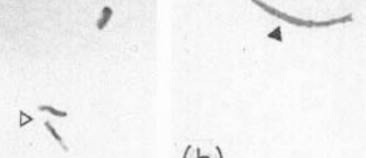

(b)

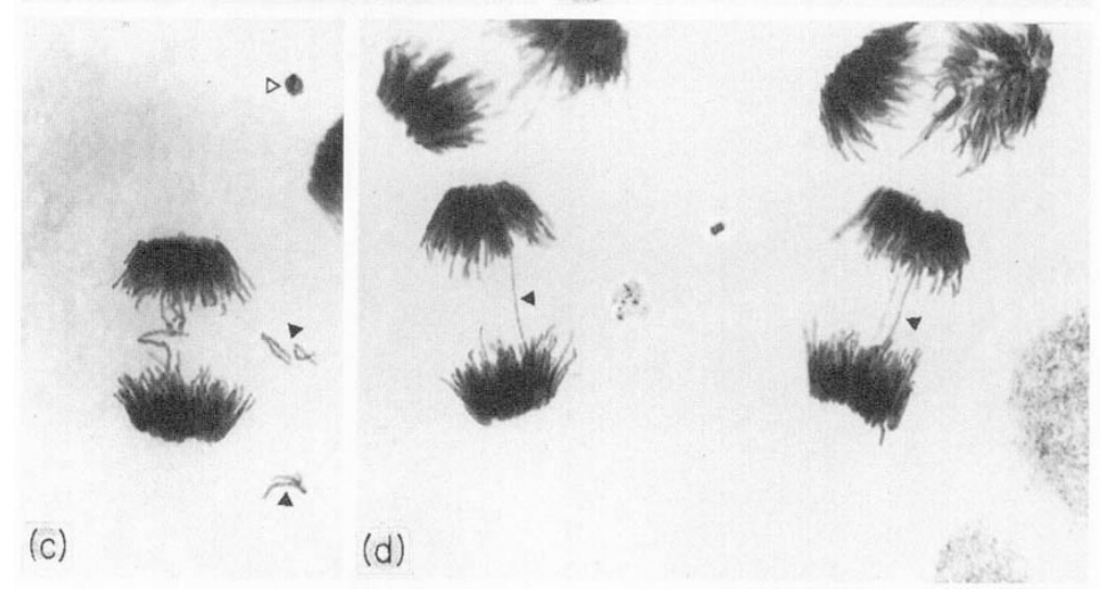

$\mathrm{CS} \times 4 \mathrm{~S}^{\mathrm{1}}(4 \mathrm{~B})$ crosses had chromosome aberrations. The results of Endo (1988a) clearly show that the dosage of chromosome $4 \mathrm{~B}$ has an important effect on the amount of chromosome damage. This may also apply to aberrations occurring during early seed development but in this present work it was not possible to determine which embryos or endosperms had the $4 \mathrm{~B}$ chromosome. Consequently only the overall frequency of aberrations could be estimated.

It is likely that some of the chromosome aberrations observed by Endo (1988a) occurred during early stages of embryo development, but is is not yet clear to what extent chromosome aberrations in somatic tissue occur during the later stages of plant growth. Further work could address this by an analysis of sector size because, for example, a particular aberration in all

\footnotetext{
*In the monosomic state chromosome 4B is transmitted to about 25 per cent of female gametes. Thus about 75 per cent of progeny from a $\mathrm{M} 4 \mathrm{~B} \times 4 \mathrm{~S}^{\mathrm{l}}(4 \mathrm{~B})$ cross will be nullisomic for $4 \mathrm{~B}$ and about $25 \mathrm{per}$ cent will be monosomic. When $\mathrm{M} 4 \mathrm{~B}$ plants are used as male parents only those pollen grains carrying a $4 \mathrm{~B}$ chromosome are competitive. Thus M4B can be considered to be equivalent to euploid CS when used as the male parent.
}

root-tips would indicate an early origin while karyotypic differences between individual roots would mean that aberrations were also occuring later in development.

Plants crossed to $4 \mathrm{~S}^{\mathrm{l}}$ containing lines do not show reduced seed set or poor seed germination even when the progeny are shown to have karyotypic changes (Endo, 1988). Thus, in contrast to the situation in cells at pollen grain mitosis 1 (PGM1), there is no evidence that aberrations in the developing seed are lethal. This may be because chromosome breakage would give partial nullisomy in meiospores but only partial monosomy or disomy in embryos and endosperms respectively. Aberrations would therefore be tolerated more easily in developing seeds. In addition, the loss of a proportion of embryo cells or endosperm nuclei early in development may be tolerated, as in the loss of cells from preimplantation mammalian embryos.

\section{(b) Comparisons of aberrations in embryo sacs and meiospores}

Many of the chromosome aberrations that occur during early embryo and endosperm development are 


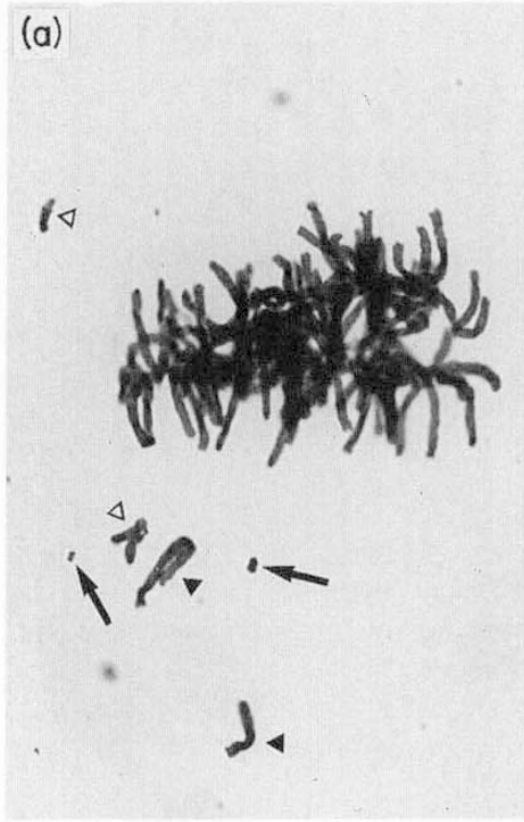

(c)

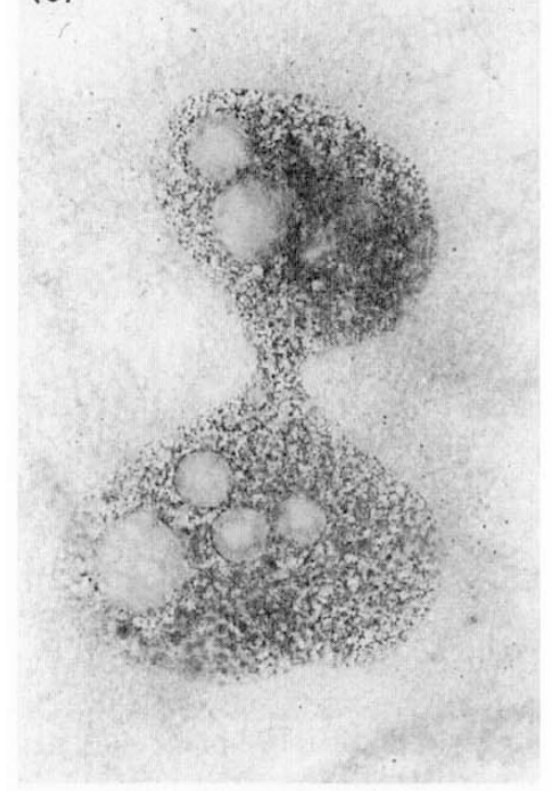

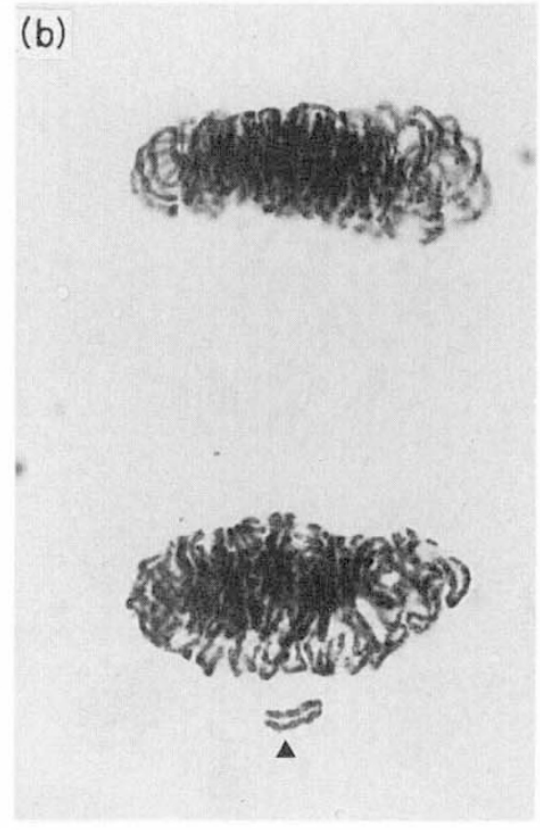

(d)

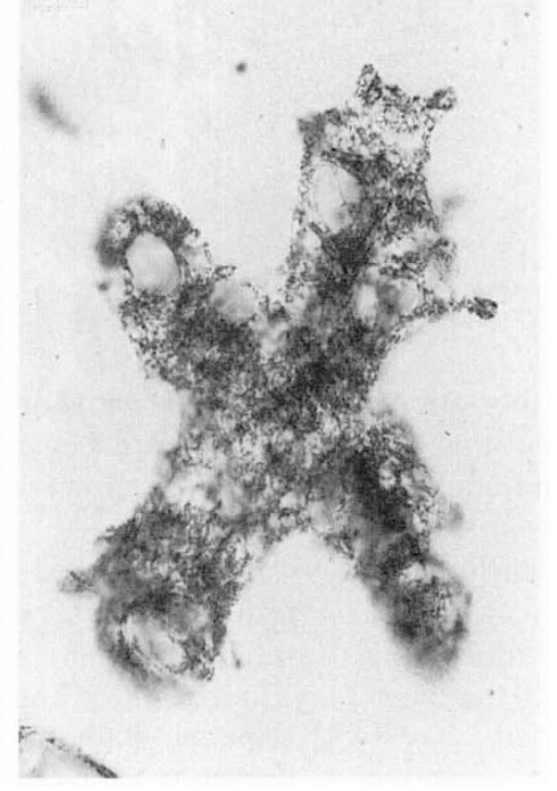

Fig. 4 Endosperms from $4 S^{\prime}(4 B)$ selfpollinations. (a) Metaphase showing type I fragments $(\boldsymbol{\Lambda})$, and other aberrations $(\Delta)$ which could not be classified as either type I or type II. This cell also shows fragments resembling double minutes $(\rightarrow)$, which are probably very small type I fragments. (b) Telophase showing a type I fragment ( $(\mathbf{\Lambda})$. (c) Two nuclei at interphase connected by a chromatin bridge. (d) A grossly abnormal large nucleus. cytologically similar to those at pollen grain mitosis 1 (PGM1). In particular, it is common to observe fragments composed of two equal length chromatids, which often appear to be associated at one end. This suggests that aberrations at PGM1 and in developing embryos and endosperms may derive from a common mechanism. Finch et al. (1984) suggested that the break points which give rise to chromosome fragments at PGM1 might be 'demarcated by the sites of meiotic chiasma formation' which are 'left eventually free by a faulty mechanism of DNA repair'. However, because similar aberrations occur in the developing embryo and endosperm (and also probably in somatic tissue in the growing plant), it seems likely that there is a more general defect. However, the mechanism of aberration induction remains unclear, and is likely to remain so until knowledge of the timing of DNA replication, transcription and translation in meiospores and the early stages of seed development is obtained. All that can be said at present is that the structure of type I fragments (Fig. 1), the occurrence of large acentric fragments and the formation of chromatin bridges suggests that U-type sister chromatid exchange may be occurring, implicating a defect at replication forks. This 
could also give rise to other types of aberration such as deletions and translocations. Further work will address this question and will also determine if the $4 \mathrm{~S}^{1}$ chromosome is preferentially transmitted in Ae. sharonensis itself, and if so whether it also causes chromosome breakage during seed development.

\section{(c) Implications of chromosome breakage for the use of chromosome $4 S^{\prime}$ in wheat breeding}

The preferential transmission of chromosome $4 S^{l}$ has a number of potentially valuable applications in wheat breeding. These include hybrid wheat production (King et al., 1991a), stabilization of semi-dwarf wheat varieties (King et al., 1991b) and the production of stable addition lines (King et al. 1992). Commercial utilization of preferential transmission requires that it be used in high yielding varieties where the induction of chromosome aberrations would be undesirable. The data presented here, and by Endo (1988a), show that this will be best facilitated by using chromosome $4 \mathrm{~S}^{\mathrm{l}}$ containing material as the female parent because this should avoid chromosome damage in the progeny plants. However, the observation that chromosome aberrations occur in the endosperm, even in self-pollinations of $4 \mathrm{~S}^{\prime}(4 \mathrm{~B})$ plants, suggests that endosperm damage may not easily be avoidable. If so it will be important to determine if this has a significant effect on final grain weight or grain quality because this would obviously be agronomically undesirable.

\section{References}

DRISCOLL, C. J. AND SEARS, E. R. 1971. Individual addition of the chromosomes of Imperial rye to wheat. Agron. Abstr., 6.

ENDO, T. R. 1985. Two types of gametocidal chromosome of Aegilops sharonensis and Aegilops longissima. Jpn J. Genet., 60, 125-135.

ENDO, T. R. 1988a. Chromosome mutations induced by gametocidal chromosomes in common wheat. In: Miller, T. E. and Koebner, R. M. D. (eds), Proceedings of the 7th International Wheat Genetics Symposium. Institute of Plant Sciences Research, Cambridge Laboratory, Cambridge, pp. 259-265.
ENDO, T. R. 1988b. Induction of chromosomal structural changes by a chromosome of Aegilops cylindrica L. in common wheat. J. Hered., 79, 366-370.

ENDO, T. R. AND MUKAI, Y. 1988. Chromosome mapping of a speltoid suppression gene of Triticum aestivum $\mathrm{L}$. based on partial deletions in the long arm of chromosome $5 \mathrm{~A}$. Jpn J. Genet., 63, 501-505.

ENDO, T. R. AND TSUNEWAKI, K. 1975. Sterility of common wheat with Aegilops triuncialis cytoplasm. J. Hered., 66, 13-18.

FinCH, R. A., MilleR, T. E. AND BENNETT, M. D. 1984. 'Cuckoo' Aegilops addition chromosome in wheat ensures its transmission by causing chromosome breaks in meiospores lacking it. Chromosoma, 90, 84-88.

KING, I. P., KOEBNER, R. M. D., READER, S. M. AND MILLER, T. E. 1991 a. Induction of a mutation in the male fertility gene of the preferentially transmitted Aegilops sharonensis chromosome $4 \mathrm{~S}^{\mathrm{l}}$ and its application for hybrid wheat production. Euphytica, 54, 33-39.

KING, I. P., KOEBNER, R. M. D., SCHLEGEL, R., READER, S. M., MILLER, T. E. AND LAW, C. N. 1991b. Exploitation of a preferentially transmitted chromosome from Aegilops sharonensis for the elimination of segregation for height in semi-dwarf bread wheat varieties. Genome, 34, 944-949.

KING, I. P., MILLER, T. E. AND KOEBNER, R. M. D. 1991c. Determination of the transmission frequency of chromosome $4 S^{\prime}$ of Aegilops sharonensis in a range of genetic backgrounds. Theor. Appl. Genet., 81, 519-523.

KING, I. P., PURDIE, K. A., MILLER, T. E., LAW, C. N. AND ROGERS, W. J. 1992. Exploitation of chromosome $4 \mathrm{~S}^{\mathrm{l}}$, from Aegilops sharonensis for the production of stable 44 chromosome wheat. Heredity, 69, 160-165.

MAAN, s. s. 1975. Exclusive preferential transmission of an alien chromosome in common wheat. Crop. Sci., 15, 287-292.

MILlER, T. E., HUTCHINSON, J. AND CHAPMAN, v. 1982. Investigation of a preferentially transmitted Aegilops sharonensis chromosome in wheat. Theor. Appl. Genet., 61, 27-33.

SEARS, E. R. 1954. The aneuploids of common wheat. Bull. Mo. Agric. Exp. Sta., 572, 3-58.

TSUJIMOTO, H. AND TSUNEWAKI, K. 1985. Gametocidal genes in wheat and its relatives. II. Suppressor of the $3 \mathrm{C}$ gametocidal gene of Aegilops triuncialis. Can. J. Genet. Cytol., 27, $178-185$.

TSUIMOTO, H. AND TSUNEWAKI, K. 1988. Gametocidal genes in wheat and its relatives. III. Chromosome location and effects of two Aegilops speltoides derived gametocidal genes in common wheat. Genome, 30, 239-244. 